\title{
The role of evidence in general managers' decision-making
}

\author{
Jan Francis-Smythe \\ Worcester Business School, University of Worcester, UK \\ Laurie Robinson \\ Worcester Business School, University of Worcester, UK \\ Catharine Ross \\ Worcester Business School, University of Worcester, UK
}

This paper presents an overview of current academic theory on evidence-based management (EBM) and considers the extent to which the decision-making processes of 39 senior, general managers are consistent with this thinking. In the pursuit of this aim the study has utilised inductive reasoning, qualitative data, purposeful sampling and semi-structured interviews, based upon the critical incident technique (Flanagan, 1954), to obtain detailed information regarding the decision-making processes utilised by each of the interviewees in relation to their most challenging managerial situations. It has been shown that these interviewees utilised only one of the four main sources of evidence for management decision-making proposed by Briner and Rousseau (20I I). In the light of this finding, ways are identified in which managers may be able to enhance their business practice by utilising more sources of evidence. In addition, the study has also identified ways in which current academic thinking needs to be developed so that it incorporates all of the practices that general managers have utilised. Finally, the implications for general managers are discussed.

\section{Introduction}

According to Rousseau (2012: p. 14) 'the basic work of management is decision-making'. How managers go about their everyday decision-making has been of interest to scholars and practitioners alike for many years with a plethora of academic papers and self-help books devoted to analysing and improving the process. A variety of models of decision-making have been introduced ranging from the early rational and bounded-rational (Simon, 1959) through to incremental (Quinn, 1981), garbage can (Cohen, March and Olsen, 1972) and random choice models (Mintzberg, 1978). Most of the focus has been on the rational model (where outcomes are sought to be maximised and the choice is rational and deliberate) and the bounded rational (where accepting both the cognitive limitations of the manager and the complexity of the situation one simply seeks to achieve sufficient outcomes). Much of this focus has also been on operational level management and not strategic level general management. Typically, Storey and Salaman in 2005 called for a focus 
on the 'know what and know how of senior level decision makers'. Rahman and deFeis (2009) suggest that for strategic managers the appropriate model changes when the characteristics of the environment change, particularly in relation to complexity and time pressure. Others have explored bias in strategic decision-making that limits rational choices such as vividness (paying attention to the bright and innovative versus hard fact), over-reach (going beyond competence as the option looks too good to refuse), pattern matching (assuming one case is like another), past success (engenders unrealistic risk assessment), escalation commitment (avoiding sunk costs) and entrapment (commitment increases with time) (Hodgson and Drummond, 2009) and politics (Bartlett, 2011). More recently however, through separate approaches, there has been much interest in the role of 'evidence' and 'intuition' in managerial decision-making (not specifically in general management). This paper seeks to bring these two literatures together by considering the current and potential role of evidence and intuition in supporting senior general managers in their everyday managerial decision-making by exploring, through an empirical study, the kinds of evidence that are currently prevalent in the decision-making processes of some senior general managers. The paper concludes by considering implications of the findings for both theory and practice.

\section{Evidence-based management}

'Evidence-based management (EBM) is the systematic, evidence-informed practice of management, incorporating scientific knowledge in the content and process of making decisions'. (Rousseau, 2012: p. 6). EBM as a concept is not new; its origins are believed to stem from evidence-based practice in medicine (Hewinson, 1977). It entered the public sector via the probation service, education, policing and social work as a matter of 'public policy' (i.e. 'politics') but is reported to have gained less popularity in the private sector (Rousseau, 2006). Much of the recent literature supports the notion that practicing EBM will enhance organisational effectiveness (Damore, 2006; Pfeffer and Sutton, 2006; Rousseau, 2006; Briner et al. 2009) but it must be acknowledged that this is currently mainly 'opinion' rather than based on empirical evidence. Some are not so sure and consider whether EBM is or is not the solution to all management challenges. In 2009, Reay et al. undertook a meta-analysis of 144 journal articles relating to evidence-based management and in response to their central question 'Is there evidence that employing evidence-based management will improve organisational performance?' indicated that 'the short answer to this question is no' (Reay et al., 2009: p. 13). In medicine there have been similar critics basing their concerns around such issues as medical practice being as much an art as a science, a lack of faith regarding the scientific process and the absence of convincing evidence that the application of research findings produces better results than reliance on experience and personal judgment (Speicher-Bocija and Adams, 2013). Even strong advocates acknowledge that for managers the challenge is greater than in other disciplines, both because 'the evidence is weaker' and because 'companies vary so wildly in size, form, and age, compared with human 
beings, it is far more risky in business to presume that a proven 'cure' developed in one place will be effective elsewhere' (Pfeffer and Sutton, 2006: p. 3). For general managers who focus on complex, multilevel and unique 'macro' or strategic issues, the challenges are greater still and it is suggested they would be more likely to value experience over evidence (Madhavan and Mahoney, 2013; Speicher-Bocija and Adams, 2013).

As well as a lack of evidence on the effectiveness of EBM there is a similar lack of evidence showing the extent to which evidence-based management is or is not actually practised (Reay et al. 2009). Despite Rousseau's (2006: p. 257) suggestions that '.. . managers, including those with MBAs, continue to rely largely on personal experience, to the exclusion of more systematic knowledge' and 'lacking shared scientific knowledge to add weight to an evidencebased decision, managers commonly rely on other bases (e.g. experience, formal power, incentives and threats) when making decisions ...' there is little empirical evidence to support this. Implicit in this comment is an assumption that MBA- educated managers are no more likely to use EBM than non-MBAs. Indeed, there is also evidence to suggest MBAs are not taught to know or use research evidence in their decision-making (Jelley et al., 2012) and yet, other disciplines have provided evidence to suggest that higher educational attainment is associated with more positive attitudes to evidence-based practice (Aarons, 2004). Thus, despite an increasingly vocal EBM movement, there is still the need for more direct evidence of both its benefits, the kind of evidence that is used in practice and the role of educational engagement and attainment in this. A number of writers also propose that EBM results in an 'evidential hierarchy' that not only favours certain kinds of 'research evidence' (randomised control trials and positivist, quantitative research paradigms), but which also results in less importance being given to other aspects of managerial decision-making, such as instinct, intuition and experience (Harrison, 1998; Marks, 2002; Learmonth and Harding, 2006; Rousseau, 2006; Arndt and Bigelow, 2007; Morrell, 2008; Reay et al., 2009; Hovmand and Gillespie, 2010). However, a more recent conceptualisation of EBM broadens the 'evidence base' from the originally narrower views of the more academic type of evidence sources to those including expertise and judgment, local context data, stakeholder opinion and ethical considerations:

'Evidence-based management is about making decisions through the conscientious, explicit, and judicious use of four sources of information: practitioner expertise and judgement, evidence from the local context, a critical evaluation of the best available research evidence, and the perspectives of those people who might be affected by the decision'

(Briner et al., 2009: p. 19).

The four sources are elaborated as follows (adapted from Briner and Rousseau, 2011):

- Practitioner expertise and judgement: Has it been seen before? What happened? What's worked in the past and why? What are my hunches? What do I think are the causes and possible solutions? Is this happening elsewhere? How relevant and applicable is my experience? 
- Evidence from the local context: What are the facts (data)? What are the local explanations? What are we currently doing and is it working? What do managers think is going on? What are the costs and benefits of interventions? What is happening or what is going to happen in the organisation or outside that might be affecting it?

- Critical evaluation of best research evidence: How does my local data compare to others? What does systematically reviewed research evidence suggest to be the major cause? How relevant and applicable is that evidence here? What does research evidence suggest as effective interventions? How well might they work here?

- Perspectives of those who may be affected: How do employees feel about proposed interventions? Do they see disadvantages? How do managers feel about the interventions? How workable are they? What alternatives have others proposed?

Briner et al. suggest that the strength of each source's influence will vary with each decision. However, still at the heart of the concept is the notion of the conscious use of evidence and the choice to place more or less emphasis on various elements being made in a mindful and deliberate way.

\section{Intuition in management decision-making}

Recent approaches in decision-making literature have paid increasing attention to intuition (Salas et. al., 2010). By defining intuition as 'affectivelycharged judgments that arise through rapid, non-conscious, and holistic associations' (Dane and Pratt, 2007: p. 40), it can be seen how this is a major departure from the rational model. However, Hodgkinson et al. (2008) propose that dual-processing theories in social cognition and cognitive psychology offer a useful way of seeing how these two supposedly opposing positions may be accommodated. Typically, cognitive-experiential self theory (CEST - Epstein, 1991) suggests the rational system operates at the conscious level, is analytic, verbal and relatively affect-free enabling information to be obtained through effortful engagement, whereas the experiential system, which Hodgkinson et al. (2008) deem as 'intuition', operates on an automatic, non-verbal, emotional, pre-conscious basis. The two systems (analytic and intuitive) are proposed to operate in tandem but can sometimes produce conflicts between 'the heart and the head' (Epstein, 2000:p. 671). Much recent work has shown how intuition is critical to effective decision-making in a variety of settings and is now deemed to be a valid construct within the organisational sciences (Salas et al., 2010). So what is meant by 'evidence' in EBM? Does it include the information used in both the analytic and the intuitive systems or just the analytic? This point perhaps remains unclear, as yet, in the conceptualisation espoused by Briner et al. (2009) where the definition might suggest analytic but the contextual debate might suggest both. They propose that even when one uses evidence unconsciously and automatically it is still evidence, citing by way of example intuition draws on the evidence of experience' (Dane and Pratt, 2007). This uncertainty is also expressed in some of the EBM literature which suggests, as noted earlier, that less importance is being given in the EBM debate to other aspects of 
managerial decision-making, such as instinct, intuition and experience. Thus, whilst there has been a tendency, in the past, in the EBM movement to minimise/disregard the role of intuition in managerial decision-making, the recent level of interest in this topic makes it timely to re-visit its potential role in helping to define EBM.

Given then that a) there is little evidence on the prevalence of the use of EBM by general managers and $b$ ) there is some ambiguity in the literature as to i) what constitutes 'evidence' (is it just the more scientific forms or does it include intuition, hunches etc.?) and ii) whether current engagement in a significant educational experience such as an MBA (when the exposure to research evidence might be at its most obvious and detectable) might influence the kind of evidence used, this paper seeks to address the research gap by posing the question: 'What kind of 'evidence' do senior general managers currently use in their decision-making and is this influenced by current engagement in an MBA learning program?' The research is inductive and as such first seeks to document the decision-making processes of some senior general managers without reference to pre-existing ideas on evidencebased decision-making. The framework of sources of evidence provided by Briner and Rousseau (2011) is then used to interpret the findings and the implications for both theory and practice are discussed.

\section{Method}

The study utilised inductive reasoning, qualitative data, purposeful sampling and semi-structured interviews to examine the decision-making process of experienced senior managers. Data was collected through verbatim transcripts of semi-structured recorded interviews from two different sources. The first set of transcripts resulted from 24 face-to- face interviews conducted with established, senior managers from five different organisations. The employing organisations were a mix of public, private and third sector firms. Of the 24 individuals interviewed via their organisations, 23 were either graduates or professionally qualified to an equivalent level; six had a Masters qualification in management; five had a management qualification at either Diploma, or Certificate level; ten had participated in comprehensive 'in house' management development training programmes and four had attended short courses at a variety of established business schools. The second set of transcripts resulted from 15 telephone interviews conducted with similarly experienced, established senior managers from a variety of organisations, who were in the midst of part-time study for an MBA at one University which placed a specific emphasis on advanced research methods and the use of research evidence. For the sake of convenience, these two samples will be referred to respectively by the short hand form of the 'general sample' and the 'currently studying' sample. The typical age of the interviewees was between 30 and 50 years and 18 of the interviewees were female and 21 were male. Each of the 39 interviewees worked within established, rather than emergent, organisations with a minimum size of 200 people and each of the interviewees also had personal responsibility for a team of at least ten people. Each interviewee met the following criteria for a 'senior manager': someone who contributed to the 
creation of a strategic plan, rather than simply implementing one; who had a measure of organisational responsibility, rather than simply departmental; who was required to deal with complexity and ambiguity, rather than simply the routine; and who was required to proactively identify and implement solutions, rather than simply recognise and communicate concerns. In organisational terms the overwhelming majority of interviewees were 'heads of service' reporting to a Director and in addition, a small number were actually Directors.

The semi-structured interviews were based upon the 'critical incident technique' (Flanagan, 1954). In this regard, each of the interviews sought to obtain detailed information regarding the decision-making processes used by each of the interviewees in relation to their most challenging managerial situations, both currently and historically. This approach was adopted on the basis that it seemed probable that it would be in relation to their most challenging and problematical of circumstances that the interviewees might be expected to consider the widest possible range of options and the broadest possible range of information. Similarly, it was decided that both current and historic challenges should be included because this had the potential to limit the extent of any recall bias. Interviewees were initially asked to identify two or three of their most significant, current, managerial challenges and later, two or three of the most challenging managerial situations that they had experienced in the whole of their career to date. Each interviewee was then asked to disclose, in some detail, the approach that they had taken to addressing each of these managerial challenges as well as the reasoning for each of the approaches that they had adopted. The interviews provided information in relation to 160 critical incidents, the verbatim transcripts totalled 355,000 words and recorded interviews lasted a total of 34 hours 53 minutes (average length 54 minutes).

\section{Data analysis}

Subsequently, the 355,000 word transcripts of the 39 interviews were subjected to a thematic analysis (Bryman, 2012) using the facilities in MS Word for highlighting, commenting and extracting. Sections of text were selected on the basis that they shed some light upon the basis of the interviewees' decisionmaking and stood out against the 'background noise' of the overall interview. Then 888 sections of the dialogue were extracted and ultimately 577 of these were attributed to one of five themes identified by one researcher.

(1) Emergent decision-building in collaboration with others.

(2) Recognition-based decision-taking.

(3) Emergent decision-building based upon previous experience/personal reflection.

(4) Emergent decision-building influenced by personal values.

(5) Emergent decision-building based upon trial and error.

All of the coding was subsequently verified and validated by two experienced co-researchers working independently. To maximise validity and reliability a range of qualitative techniques were utilised including the 
extraction of rich and thick descriptions, the inclusion of negative or discrepant information (see later section) and the provision of information to the interviewees in order that they might comment upon the findings and the use of peer debriefing to review and question the research study and analysis (Cresswell, 2003). Indicating the total number of extracts coded to each theme provides an indication of the relative weight of data as it relates to each of the themes. In order that some appreciation can be gained for the generality of each theme across all of the interviews, both the overall number of interviewees and the percentage of interviewees supplying the extracts is also given. This numerical analysis also provides data which enables an indicative assessment to be made of the influence of MBA learning upon the types of evidence that these senior general managers utilised. In this regard, the percentage of the two samples contributing extracts to each theme is given as well as the total percentage of the samples' extracts that could be linked to the theme. This allows the relative importance of each theme to be assessed for each of the two samples. This data is portrayed at the end of each theme and in tabular form in Table 1.

\section{Findings}

\section{Emergent decision-building - in collaboration with others}

The most common way in which the interviewees sought to address their most significant challenges was by discussing the situation with their fellow professionals, including peers, colleagues, bosses, mentors, facilitators and trusted advisers. Two hundred and seventy-two extracts from the total of 577 provided examples of this type of decision-making and 38 out of the 39 interviewees (97\%) gave examples of it. In addition, $100 \%$ of the general sample and $93 \%$ of the 'currently studying sample' contributed one or more extract and $52 \%$ of the 'general sample' extracts and $30 \%$ of the 'currently studying sample' extracts could be 'indexed' to this category. The key requirement was for the people who were consulted to have gained both the trust and the confidence of the interviewee and for them to also have a track record as successful practitioners. The interviewees utilised their extensive personal networks, both inside and beyond their current organisations, to identify such individuals and this included individuals from within both their supply chain and their contractor base. Ultimately, if the issue was sufficiently significant and the person sufficiently senior, this could result in receiving feebased advice from a consultant. However, this was very much the exception. Within the transcripts the kind of example provided by the interviewees were as follows:

'I tap into my network both internally within the company and also externally within the suppliers and within the customer base'.

'Talking to other people, my peers, just other Heads, about... (pause)... you know, what they might do in their approach'.

'I think what we recognised is that we needed some expertise around that, somebody, as you say, that can really... help us shape what our approach should be'. 


\begin{tabular}{|c|c|c|c|c|c|}
\hline \multirow{2}{*}{ 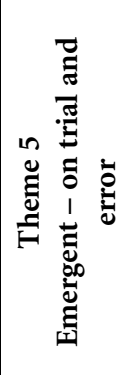 } & 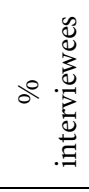 & $F$ & 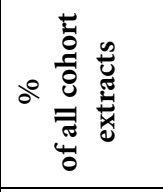 & 6 & $=$ \\
\hline & 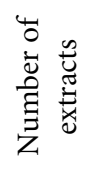 & F & 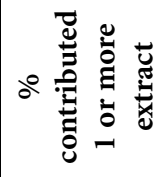 & in & ㅇ \\
\hline \multirow{2}{*}{ 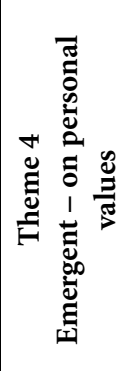 } & 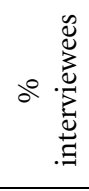 & $\ddot{H}$ & 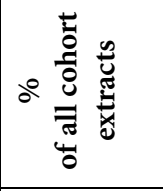 & $\infty$ & $\simeq$ \\
\hline & 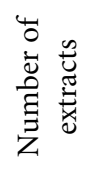 & in & 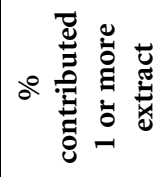 & $\hat{6}$ & $m$ \\
\hline \multirow{2}{*}{ 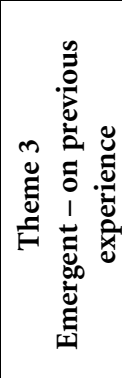 } & 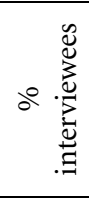 & হ & 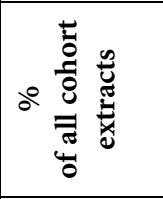 & 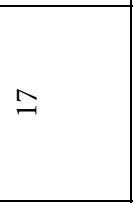 & $=$ \\
\hline & 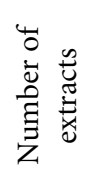 & $\bar{\sigma}$ & 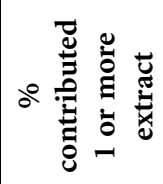 & $\infty$ & $\hat{\sigma}$ \\
\hline \multirow{2}{*}{ 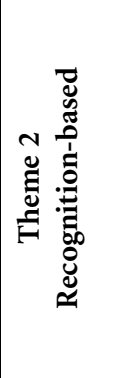 } & 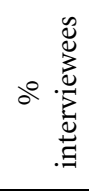 & $\curvearrowright$ & 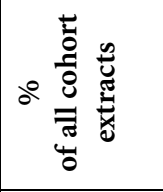 & 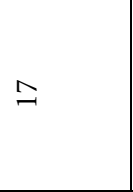 & $\stackrel{n}{m}$ \\
\hline & 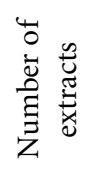 & $\vec{\beth}$ & 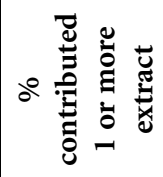 & $\infty$ & 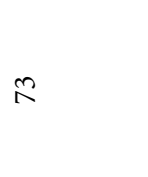 \\
\hline \multirow{3}{*}{ 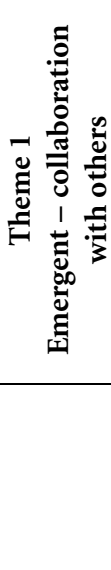 } & 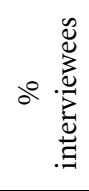 & à & 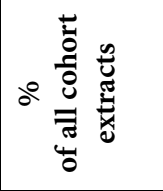 & กิ & i \\
\hline & 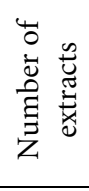 & $\stackrel{\mathbb{N}}{\mathbb{N}}$ & 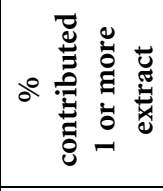 & $\nsubseteq$ & $\alpha$ \\
\hline & & 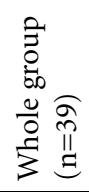 & & 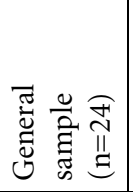 & 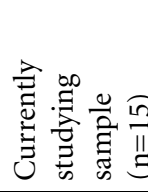 \\
\hline
\end{tabular}


These findings support the views that peer relationships within organisations are the context within which sense-making and assuming a consultative role and passing on wisdom can take place (Kram and Isabella, 1985; Peroune, 2007) and that management can, at least in part, be characterised as a craft learnt through lifelong collaboration with other practitioners in a 'community of practice' (Lave and Wenger, 1991).

\section{Recognition-based decision-taking}

The second most common way in which these interviewees reacted to the most challenging situations and circumstances that arose around them was by recognition. In this instance, 121 extracts from the total of 577 extracts and examples of this type of decision-making were provided by 31 of the 39 interviewees (79\%). In addition, $83 \%$ of the 'general sample' and $73 \%$ of the 'currently studying sample' contributed one or more extracts and $17 \%$ of the 'general sample' extracts and $35 \%$ of the 'currently studying sample' extracts could be 'indexed' to this category. This was that they simply knew what the organisational signs and symptoms meant, or implied; they knew what worked, they knew the approach to take and they knew that the implementation of these instantly recognisable and retrievable remedies would result in the situation being stabilised and the signs and symptoms being ameliorated. This is known as 'recognition based decision-taking' (Klein, 1998) and the kind of words that the interviewees used to describe this phenomenon were experience, instinct, experiential, common sense, subconscious, intuitive, informal, reactive, immediate, practical as well as:

'A wing and a prayer'; 'I'll just rock up and do it'; 'A no brainer'; 'Instinct in a word'; 'I think its intuition'; 'Blindingly obvious'; 'Common sense'; 'Gut instinct'; 'Years of experience'.

Given that these interviewees were describing their most significant current and previous managerial challenges it may, at first glance, appear surprising that so many of these might be susceptible to this kind of recognition-based decision-taking. However, there may well be subtle but important distinctions between the scale of any challenge, the clarity of the signs and symptoms, the certainty of the manager's diagnosis, the assuredness of the proposed remedial action, the prospects for success and the consequences of an unsuccessful outcome. Hence, there may be no link between the complexity of the prevailing circumstances and either the appropriateness, or the viability of recognition-based decision-taking.

\section{Emergent decision-building based on previous experience}

Previous experience was also a common basis for decision-making. This analysis was based on 91 extracts from the total of 577 extracts and examples of this type of decision-making were also provided by 31 of the 39 interviewees (79\%). In addition, $88 \%$ of the 'general sample' and $67 \%$ of the 'currently studying sample' contributed one or more extract and $17 \%$ of the 'general sample' extracts and $11 \%$ of the 'currently studying sample' extracts could be 
'indexed' to this category. Inevitably, there were some situations that could not be handled in this 'recognition-based' way and accordingly, a process of 'emergent decision-building', based on previous experience was applied to construct a single, viable approach which they believed had the features and characteristics that were necessary to address the organisational situation that was concerning them. Within the interview transcripts the kinds of words that the interviewees use to describe this phenomenon were 'gradual', 'evolving', 'discovering', 'emergent' and 'considered'. Some representations of this generic approach are as follows:

'It's more emergent, I think actually, in terms of how I decide things'.

'It's really something that did evolve rather than be something which was

seeing an immediate problem and saying 'Right, yes, we need to do it'.

It is in these kinds of uncertain, or unclear situations that the interviewees may have been expected to adopt a more rational approach to strategic decisions. It is in this context that evidence from academic research, text books, theory, ideas, concepts and models, together with formal training and education in management might also be expected to play some kind of part although within these interview transcripts there was little evidence of this kind of input. As part of the emergent decision-building process the interviewees demonstrated extra-ordinary levels of personal reflection. Within the transcripts the kind of examples that interviewees provided in support of the general role of their reflective practices were as follows:

'It was only when I discovered that, actually it didn't roll smooth, flow as smoothly as I expected it to, that I had to start thinking'.

'I mean, the big influence for me is the ability to reflect'.

'Experience tells me, that it is, ... it is useful to rewind the tape and think'.

In addition, there appeared to be both a willingness and an ability to sift through similar, related experiences and to deconstruct these, so that elements of a number of experiences could be reconstructed to form an untried, but potentially viable approach.

\section{Emergent decision-building influenced by personal values}

For a significant minority of the interviewees a major factor in their 'emergent decision- building' was the overt application of a clear set of personal values. There were 52 extracts from the total of 577 extracts and examples of this type of decision-making were provided by 21 of the 39 interviewees $(54 \%)$. In addition, $67 \%$ of the 'general sample' and $33 \%$ of the 'currently studying sample' contributed one or more extracts and $8 \%$ of the 'general sample' extracts and $12 \%$ of the 'currently studying sample' extracts could be 'indexed' to this category. These values were used as both a compass to steer by and as a means of ruling out some potential approaches on the basis that they would be unprofessional, culturally unacceptable, or simply not how people should be treated. Within the transcripts the kind of examples provided by the interviewees were as follows:

'A lot of it is a personal value'. 
'So it was quite a difficult situation and our styles and values were enormously different and it caused me a lot of soul searching'.

'I'll talk more about work when there's $a, \ldots$ er ... something that's against my principles or values'.

This is clearly showing how 'power and politics' as described by Bartlett (2011) may well influence the decision-making process and these managers are saying they are guided in a very positive way by their own personal values against some of these negative external influences.

\section{Emergent decision-building based on trial and error}

Only 41 extracts from the total of 577 extracts were based on trial and error and examples of this type of decision-making were provided by 16 of the 39 interviewees (41\%). In addition, 54\% of the 'general sample' and $20 \%$ of the 'currently studying sample' contributed one or more extracts and $6 \%$ of the 'general sample' extracts and $11 \%$ of the 'currently studying sample' extracts could be 'indexed' to this category. Some interviewees also showed that an additional component of the emergent decision-building approach was the willingness to utilise trial and error, to experiment and to make progress, at least in the short term, via very small incremental steps whilst closely monitoring the impact via both hard and soft measures. Klein (1998) describes this phenomenon as the preference of managers for 'hedge clipping to tree felling'. The following are examples of this kind of phenomenon:

'A lot of it was learning on the job, learning as we went along. If things didn't work out, we'd adjust them, try them again, re-adjust, re-evaluate, that sort of thing really'.

'It was a case of testing stuff out, getting new information, making decisions based on that, trying it differently'.

'I think this management thing, it's all about behaviours. It's difficult to learn in a book but you have to try different approaches, don't be afraid to try something'.

\section{Summary of analysis}

In summary, the first point to note is that taking the whole cohort $80 \%$ or more of the interviewees provided extracts relating to themes 1,2 and 3 , over $50 \%$ for theme 4 and roughly $40 \%$ for theme 5 . This suggests the themes were well represented across interviewees and are thus representative of the sample as a whole. By considering actual numbers of extracts it would appear that theme 1 (collaboration with others) is overwhelmingly more prevalent than any of the others, closely followed by themes 2 and 3 (recognition-based and previous experience) with 4 and 5 (personal values and trial and error) considerably less so. The fact that 'trial and error' occurred least may well be related to the fact that managers were asked to reflect on their most challenging managerial situations, situations in which it might be envisaged that these types of situation are less likely to require only incremental or piecemeal changes. When considering the data by level of current educational engagement it appears that for themes 1, 2 and 3 the contributions were 
reasonably well spread across both samples. However, for both themes 4 and 5 (personal values and trial and error) the extracts were far less well distributed across fewer people in the 'currently studying sample'. Thus theme 1 (collaboration with others) is most prevalent for the 'general sample' whereas theme 2 (recognition-based) is most prevalent for 'currently studying sample'. Themes 3, 4 and 5 (previous experience, personal values and trial and error) have reasonably similar weightings in both.

\section{Interpretation of findings and discussion}

Having identified from the data five themes and their relative representations both within and across the both the 'general sample' and the 'currently studying sample' the next stage was to interpret these findings in the light of the existing literature on evidence-based decision- making. This was achieved by comparing and contrasting the empirical findings from this study with the framework proposed by Briner and Rousseau (2011) which proposes four sources of evidence (ES1 - ES4) relevant to evidence-based management decision-making:

(1) Practitioner expertise and judgment (ES1).

(2) Evidence from the local context (ES2).

(3) Critical evaluation of best available research evidence (ES3).

(4) Perspectives of those who may be affected by the intervention decision (ES4).

Each of the five themes identified here were examined for 'fit' with the four 'sources' listed above by comparing the detailed descriptions in the analysis section of this paper alongside the specific questions/sources cited earlier in the introduction for the Briner and Rousseau (2011) framework.

\section{Emergent decision-making in collaboration with others, notably the influence of fellow professionals, such as peers, colleagues, bosses, mentors, facilitators and other trusted advisers}

Whilst this is similar to ES4 in terms of 'What alternative explanations and proposed solutions do others have?', ES4 refers specifically to 'those who may be affected by the intervention decision' whereas these interviewees identified many other people not involved in the challenge as 'sources of evidence/ information' who would be involved in a collaborative way. It might also be considered as somewhat similar to ES1 - practitioner expertise and judgement but applied to 'other practitioners'. This provides specific evidence on the important role of communities of practice as suggested by Lave and Wenger (1991). 
Recognition-based decision-taking, including decision-making by what the interviewees described using words such as experience, instinct, experiential, common sense, subconscious, intuitive, informal, reactive, immediate, practical

Whilst this is similar to ES1 - practitioner expertise and judgment, the focus of ES1 is predominantly 'conscious evaluation' and as currently formulated focuses less on the kind of 'immediate, instinctive, intuitive, sub-conscious' nature of this type of decision-taking as identified by the interviewees. The only reference to this in ES1 is 'what are my hunches?' but even this implies cognition rather than instinct, intuition and sub-conscious and this more 'reflex-based' decision-taking. This finding therefore supports comments in the EBM literature suggesting less importance was being given in the EBM debate to other aspects of managerial decision-making, such as instinct, intuition and experience (Harrison, 1998; Marks, 2002; Learmonth and Harding, 2006; Rousseau, 2006; Arndt and Bigelow, 2007; Morrell, 2008; Reay et al., 2009; Hovmand and Gillespie, 2010) and supports the suggestions in the decision-making literature of the importance of intuition for strategic managers (Hodgkinson, et al., 2009).

Emergent decision-building based on personal experience (including decision- taking by what the interviewees described by words such as 'gradual', 'evolving', 'discovering', 'emergent' and 'considered') and on personal reflection (an extensive, largely unstructured, slightly chaotic and highly intrusive process; including the deconstruction and subsequent reconstruction of previous experiences)

Once again, there appears to be some congruence between this type of 'decision-building', as described by the interviewees, and ES1 practitioner expertise and judgment. However, ES1 does not specifically highlight the deconstruction and reconstruction (Bartlett, 1967) aspects of this type of decision-building and once again these characteristics were specifically identified by the interviewees.

Emergent decision-building influenced by personal values, including ruling out some potential approaches on the basis that they would be unprofessional, culturally unacceptable, or simply not how people should be treated

In a general way, this might be regarded as being potentially similar to both ES1 and ES4, although neither makes any specific reference to ethics. In their paper, however, Briner et al. (2009: p. 23) suggest 'the views of stakeholders and those likely to be affected by the decision would be considered, along with ethical implications of the decision'. ES1 appears to be clearly about both practical 'expertise' and the critical 'evaluation' of options on pragmatic 
grounds. ES4 appears to be clearly about the potential reactions of both those who will be involved in the implementation of the 'intervention decision' and those who will be 'affected' by it. Hence, neither ES1 nor ES4 incorporate the spirit of that which was specifically identified by the interviewees. This was that in a very conscious and direct way they used their personal belief and values system to 'rule out' some potential decisions. This finding contributes to the current debate about the influence of ethics and politics in the EBM process which has more recently been articulated in the literature (Morrell, 2008; Bartlett, 2011), although contrasting with the findings here, where the general manager's own value system is overriding the 'political' in a positive way.

\section{Emergent decision-building based on trial and error; the willingness to experiment and the willingness to make progress, at least in the short term, via very small incremental steps}

This is not identified in any of Briner et al.'s (2009) evidence sources. This aspect of practitioner decision-building was not built around either the use of instinct and intuition or the conscious consideration of approaches from within the interviewees' established repertoire. Indeed, the 'hedge trimming' approach specifically recognises either that there is little, if any, evidence to guide either the decision-building or the implementation process or that in relation to a specific issue, such information is unnecessary. In addition, this approach to decision-building wittingly accepts that in relation to the identified issue it will be acceptable to utilise trial and error, to make progress via very small incremental steps and to monitor the outcome very closely. Hence, the essential characteristic of this approach to decision-taking is based around experimentation rather than the evaluation of evidence.

\section{Discrepant case analysis}

There appeared to be very few exceptions in the data to these general findings, although three types of exception were noted. Firstly, in situations where the circumstances effectively prevented the interviewee from adopting one of the five approaches previously mentioned, a small minority showed a willingness to consult with either academic text books or journal articles to confirm their sense-making routines, rather than as a source to inform their decisionmaking. Two examples of this type were provided, both by the 'general sample'. Typical of these are the following extracts:

'Recently this idea of my view of where the organisation finds itself, at this moment in time, in terms of merger, took me back to some of my books and I went through what 'So and So' said about it, to see if it reinforced my thinking about that, or whether I was . . completely off at a tangent'.

'I just use it as a checking process to make sure I'm on the right lines, that I understand where I'm at'.

Secondly, there were some situations in which a minority of the interviewees showed a willingness to appropriate the tools and techniques that were 
associated with some theories and models (e.g. SWOT and stakeholder analysis). Three examples of this type were provided by the general sample and a further three were provided by the current MBA sample. Typical of these are the following extracts from a 'currently studying' interviewee:

'I mean, we've recently been through, ... I'd say the last assignment that we did, was... very much around... strategy at a very high level... and some of them... I could actually see myself using. Some of them I kind of felt like I never want to look at this again . . . but other ones . . . were incredibly practical. I mean for me, in project management, stakeholder analysis is brilliant'.

Finally, there were other situations in which a small minority of the interviewees had appeared to appropriate a particular model, but where there purpose appeared to be to provide a 'metaphor' or 'language' in which the work situation could be discussed with those affected. There were three examples of this type and each was provided by the general sample. Typical of these are the following extracts, each of which refers to an interviewee's use of a particular model:

'[It] sometimes it helps provide a language for a discussion'.

'[It] helps me then explain what I, ... what I might mean, about my own ideas, to other people. It also helps to start a debate'.

This would appear to suggest that in exceptional circumstances a small minority of the interviewees were prepared to use ES3 - research evidence, but only when emergent or recognition-based decision-making failed. Interestingly, most of these examples were from the 'general sample' of interviewees who were not currently studying for an MBA. This comparison to the suggested sources of evidence useful for EBM proposed by Briner and Rousseau (2011) has shown that on the basis of the evidence provided by these interviewees, the general management decision-making routine that falls most clearly and directly within their framework as currently conceptualised, is that of 'emergent decision-building' by reference to previous experience (ES1). There is only a very small amount of evidence that research evidence (ES3) is used. In addition, the data has provided evidence for some general management decision-making routines that could not be easily or obviously located within the Briner-Rousseau model and which suggest either the use of additional/alternative sources of evidence (e.g. personal values) or the use of an already cited evidence source in a different context (ES1 from other practitioners).

\section{Conclusions}

This research sought to address the questions 'What kind of 'evidence' do senior general managers currently use in their decision-making and is this influenced by current engagement in an MBA program'. The findings showed that, when confronted with some of their most significant challenges, experienced, senior general managers most often used 'evidence' acquired from fellow professionals (internal and external to their organisation) and 
that their second-most preferred form of 'evidence' was their own intuition or instinct. Personal experience and personal values were of next importance and research evidence only used minimally. Interestingly, in this study, the managers currently studying towards an MBA tended to use intuition the most, whilst those not currently studying towards an MBA used fellow professionals the most. However, both samples used these approaches far more than research evidence. The finding that where research evidence was used it was mostly by those not currently study for an MBA is particularly interesting. Indeed, it had been anticipated that those currently study for an MBA would show a greater preference for utilising research evidence and this group of interviewees had been specifically chosen to maximise that chance. These are interesting findings in that they do generally support Rousseau's suggestion that: ' . . managers, including those with MBAs, continue to rely largely on personal experience, to the exclusion of more systematic knowledge' and 'lacking shared scientific knowledge to add weight to an evidencebased decision, managers commonly rely on other bases (e.g. experience, formal power, incentives and threats) when making decisions ...' Rousseau (2006: p. 257). However, given its specific inclusion of individuals who were currently studying for an MBA, this study might suggest that it is not necessarily the 'lacking of shared scientific knowledge' that is the reason, but simply that preference is given to intuition and peer collaboration.

The finding that intuition was the most ('currently studying sample'), or second-most ('general sample') form of evidence again provides support for the literature that claims that instinct, intuition and experience are (wrongly) given less importance than the more positivist, quantitative types of research evidence in the EBM literature (Harrison, 1998; Marks, 2002; Learmonth and Harding, 2006; Rousseau, 2006; Arndt and Bigelow: 2007; Morrell, 2008; Reay et al., 2009; Hovmand and Gillespie, 2010) and that the more recent, broader conceptualisation of EBM (Briner et al., 2009) is more appropriate. The findings from this study also suggest that the Briner framework might usefully be extended to include 'peer expertise and judgement' and 'personal values'. Traditionally, management has been thought to follow the 'craft' model where learning is through observing and emulating the behaviour of master practitioners, perhaps it is a more advanced version of this that is seen here in this study when the most often used 'evidence' is that from fellow professionals/ peers. The early definitions of EBM sat clearly in the alternate training model mode - that of the scientific model where people are encouraged to be sceptical, ask for evidence and apply critical analysis. Perhaps it is now possible to acknowledge a more mature form of EBM which will bring positive outcomes in terms of enhanced organisational effectiveness, which incorporates both modes (craft and scientific), defines 'evidence' in the broadest terms and to coin a phrase no longer 'throws the baby (intuition and experience) out with the bath water'! There is now a need for research to build on this small scale qualitative study in order to provide more 'evidence' (as opposed to opinion) on the use of EBM by senior, general managers ideally using methodologies which will provide more objective measures of behaviour such as observation, diaries, etc. and larger scale quantitative studies to draw any conclusions about the managerial population as a whole. Two 
specific aspects worth pursuing further are: i) What is the possible interplay between the role of personal values and scientific research evidence, do they tend to be in opposing positions or might they more generally align? ii) How does the kind of 'evidence' that general managers use change over time as they become more experienced and/or educated managers?

This study has shown that, in the main, senior general managers report utilising only one of the four main sources of evidence for management decision-making proposed by Briner and Rousseau (2011): practitioner expertise and judgment. Whilst it is acknowledged that this is an important and valued source of evidence it is not the only one that could be considered. Rynes et al. (2007) showed in a survey of $959 \mathrm{HR}$ professionals that more than $50 \%$ either disagreed with the usefulness of, or did not know about research findings in certain specific areas. This would suggest that in order to gain more of the espoused benefits of evidence-based management general managers could consider using more evidence from the local context, critically evaluating best research evidence such as that available from systematic reviews and academic journals and using information and views gained from those who may be affected by the decisions such as employees and managers. Zanardelli (2012) as a practicing, evidence-based, senior manager (a CEO) suggests that ongoing management development, regular reading of books and articles based on scientific evidence, the use of logic models to lay out critical information and assumptions relevant to managerial decisions, and quality relationships with local Universities and their faculty are helpful in promoting evidence-based decision-making. Developing easy access points to research evidence, establishing research-findings reading groups and using social media to link managers and researchers might also be beneficial (SpeicherBocija and Adams, 2012). Given that collaborating with peers has been shown to be so important to managers' decision-making, providing the managers currently studying towards an MBA with networking opportunities is an important component of MBA courses and an aspect to be promoted. A view perhaps supported by Hay (2006) whose study of 35 MBA graduates showed that 'exposure to different industries, organisations and international cultures' was the second most important benefit of an MBA. This paper has provided an overview of some of the current academic thinking on the practice of evidence-based management, and through a comparison with current practice of senior general managers illustrated, firstly, ways in which current academic thinking may not incorporate each of the sources of evidence/information in use by senior general managers and secondly, ways in which managers may be able to enhance their business practice by utilising more sources of evidence. As such, this study provides useful data from a small sample of senior general managers when making decisions in relation to their most challenging managerial situations.

\section{References}

Arndt, M. and Bigelow, B. (2007), 'Evidence-based management in health care organizations: A critique of its assumptions', Best Paper Proceedings of the Academy of Management, Philadelphia, PA.

Aarons, G. A. (2004), 'Mental health provider attitudes toward adoption of evidence-based 
practice: The evidence-based practice attitude scale (EBPAS)', Mental Health Services Research, No. 6. pp. 61-73.

Bartlett, Sir F. C. (1967), Remembering: A study in experimental and social psychology, Cambridge: Cambridge University Press.

Bartlett, D. (2011), 'The neglect of the political: An alternative evidence-based practice for I-O psychology', Industrial and Organisational Psychology, Vol. 4, pp. 27-31.

Briner, R. B., Denyer, D. and Rousseau, D. M. (2009), 'Evidence-based management: Concept clean-up time?', Academy of Management Perspectives, Vol. 23, No. 4, pp. 19- 32.

Briner, R. B. and Rousseau, D. M. (2011), 'Evidence-based I - O psychology: Not there yet', Industrial and Organizational Psychology, Vol. 4, pp. 3-22.

Bryman, A. (2012), Social research methods (4th edn.), Oxford: Oxford University Press.

Cohen, M. D., March, J. G. and Olsen, J. P. (1972), 'A garbage can model of organisational

Choice', Administrative Science Quarterly, Vol. 17, No. 1, pp. 1-25.

Cresswell, J. W. (2003), Research design: Qualitative, Quantitative and mixed methods approaches (2nd edn.), Thousand Oaks, CA: Sage.

Damore, J. F. (2006), 'Making evidence-based management usable in practice', Frontiers of Health Services Management, Vol. 22, No. 3, pp. 37-39.

Dane, E. and Pratt, M. G. (2007), 'Exploring intuition and its role in managerial decisionmaking', Academy of Management Review, Vol. 32, pp. 33-54.

Epstein, S. (1991), 'Cognitive-experiential self-theory: An integrative theory of personality', in: Curtis, R. C. (ed.), The relational self: Theoretical convergences in psychoanalysis and social psychology, New York: Guildford Press, pp. 111-137.

Flanagan, J. C. (1954), 'The critical incident technique', Psychological Bulletin, Vol. 51, No. 4, pp. 327-358.

Harrison, S. (1998), 'The Politics of Evidence-based Medicine', Policy and Politics, Vol. 26, pp. 15-31.

Hay, A. (2006), 'Seeing differently: Putting MBA learning into practice', International Journal of Training and Development, Vol. 10, No. 4, pp. 291-297.

Hewinson, A. (1997), 'Evidence-based medicine: What about evidence-based management?', Journal of Nursing Management, Vol. 5, pp. 195-198.

Hodgkinson, G. P., Langan-Fox, J. and Sadler-Smith, E. (2008), 'Intuition: A fundamental bridging construct in the behavioural sciences', British Journal of Psychology, Vol. 99, pp. 127.

Hodgson, J. and Drummond, H. (2009), 'Learning from fiasco and how to avoid it', Journal of General Management, Vol. 35, Issue 2, pp. 81-92.

Hovmand, P. S. and Gillespie D. F. (2010), 'Implementation of evidence-based practice and organizational performance', Journal of Behavioral Health Services and Research, Vol. 37, No.1, pp. 79-94.

Jelley, R. B., Carroll, W. R. and Rousseau, D. M. (2012), 'Reflections on teaching evidence-based management', in: Rousseau, D. M. (ed.). The Oxford Handbook of Evidence-based Management, New York: Oxford University Press, pp. 79-91.

Klein, G. (1998), The sources of power: How people make decisions, Cambridge, Mass: MIT Press.

Kram, K. E. and Isabella, L. A. (1985), 'Mentoring alternatives: The role of peer relationships in career development', Academy of Management Journal, Vol. 28, No. 1, pp. 110-132.

Lave, J. and Wenger, E. (1991), Situated learning: Legitimate peripheral participation, Cambridge: Cambridge University Press.

Learmonth, M. and Harding, N. (2006), 'Evidence-based management: The very idea', Public Administration, Vol. 84, No. 2, pp. 245-266.

Madhavan, R. and Mahoney, J. T. (2012), 'Evidence-based management in 'macro' areas: The case of strategic management', in: Rousseau, D. M. (ed.), The Oxford Handbook of Evidencebased Management, New York: Oxford University Press, pp. 79-91.

Marks, D. F. (2002), Perspectives on evidence-based practice, London: Health Development Agency.

Mintzberg, H. (1978), 'Patterns in strategy formation', Management Science, Vol. 24, pp. 934 948.

Morrell, K. (2008), 'The narrative of 'evidence based' management: A Polemic', Journal of Management Studies, Vol. 45, No. 3, pp. 613-635. 
Peroune, D. L. (2007), 'Tacit knowledge in the workplace: The facilitating role of peer relationships', Journal of European Industrial Training, Vol. 31, No. 4, pp. 244-258.

Pfeffer, J. and Sutton, R. I. (2006), 'Evidence-based management', Harvard Business Review, Vol. 84, No. 1, pp. 2-12.

Quinn, J. B. (1981), 'Formulating strategy one step at a time', Journal of Business Strategy, Vol. 1, No. 3, pp. 42-63.

Rahman, N. and de Feis, G. L. (2009), 'Strategic decision-making: models and methods in the face of complexity and time pressure', Journal of General Management, Vol. 35, Issue 2, pp. 43-59.

Reay, T., Berta, W. and Kazman Kohn, M. (2009), 'What's the evidence on evidence-based

management?', Academy of Management Perspectives, Vol. 23, No. 4, pp. 5-18.

Rousseau, D. M. (2006), 'Is there any such thing as 'evidence based management?', Academy of Management Review, Vol. 31, No. 2, pp. 256-269.

Rousseau, D. M. (2012), The Oxford Handbook of Evidence-based Management, New York: Oxford University Press.

Rynes, S. L., Giluk, T. L. and Brown, K. G. (2007), 'The very separate worlds of academic and practitioner periodicals in human resource management', Academy of Management Journal, Vol. 50, No. 5, pp. 987-1008.

Salas, E., Rosen, M. A. and Diaz Granados. D. (2010), 'Expertise-based intuition and decisionmaking in organisations', Journal of Management, Vol. 36, No. 4. pp. 941-973.

Simon, H. A. (1959), 'Theories of decision-making in economic and behavioral science',

American Economic Review, Vol. 49, pp. 253-283.

Speicher-Bocija, J. and Adams, R. (2013), 'Designing strategies for the implementation of EBM among senior management, middle management, and supervisors', in: Rousseau, D. M. (ed.), The Oxford Handbook of Evidence-based Management, New York: Oxford University Press, pp. 293-306.

Storey, J. and Salaman, G. (2005), 'The knowledge work of managers', Journal of General Management, Vol. 31, No. 2. pp. 57-73.

Zanardelli, J. (2012), 'At the intersection of the academy and practice at Asbury Heights', in: Rousseau, D. M. (ed.), The Oxford Handbook of Evidence-based Management, New York: Oxford University Press, pp. 191-197.

Dr Jan Francis-Smythe is the Director of Research and Staff Development in the Business School at the University of Worcester. She is a Chartered Occupational Psychologist and Associate Fellow of the British Psychological Society. Her specialist areas of expertise are in 'time' as it relates to both individuals and organisations, careers and in the process of knowledge transfer between universities and business and the community.

Dr Laurie Robinson is both an executive coach and mentor and a part time lecturer at the University of Worcester where he teaches research methods to MBA students. His research interest is the appropriation of ideas, theories, concepts and models by management practitioners. Prior to working as a coach and mentor, he held a number of senior executive positions in a variety of disciplines and organisations. He has also worked as a director, a non-executive director, a trustee and as the chair of a board of trustees.

Dr Catharine Ross is a Senior Lecturer in Business Management at the University of Worcester. She is a member of the Chartered Institute of Personnel and Development and her areas of expertise are the management of diversity within organisations and management development. 
